\title{
Энергетические затраты при формировании упругонапряженного состояния в слоях ступенчатого метаморфного буфера в гетероструктуре, выращенной на подложке (001) GaAs
}

\author{
(C) А.Н. Алешин ${ }^{1}$, А.С. Бугаев ${ }^{1}$, О.А. Рубан ${ }^{1}$, В.В. Сарайкин ${ }^{1}$, Н.Ю. Табачкова ${ }^{2}$, И.В. Щетинин ${ }^{2}$ \\ ${ }^{1}$ Институт сверхвысокочастотной полупроводниковой электроники им. В.Г. Мокерова \\ Российской академии наук, \\ 117105 Москва, Россия \\ ${ }^{2}$ Национальный исследовательский технологический университет „МИСиС“, \\ 119049 Москва, Россия \\ E-mail: a.n.aleshin@mail.ru
}

Поступила в Редакцию 4 апреля 2019 г.

В окончательной редакции 12 апреля 2019 г.

Принята к публикации 12 апреля 2019 г.

На основе данных рентгеноструктурного анализа, выполненного методом построения карт обратного пространства, а также исследований с применением вторично-ионной масс-спектрометрии и просвечивающей электронной микроскопии показано, что в многослойной эпитаксиальной гетероструктуре, содержащей метаморфный ступенчатый буфер, наряду с латеральными сжимающими напряжениями возникают также и вертикальные сжимающие напряжения. Причиной появления вертикальных напряжений является эффект межслоевого упрочнения, возникающий из-за торможения фрагментов скользящих дислокаций межфазными границами. Выполненный в рамках линейной теории упругости анализ показал, что упругонапряженное состояние ступеней буфера аналогично состоянию, которое может быть достигнуто в результате двухстадийного деформационного процесса: всестороннего и двухосного сжатия. Всестороннее сжатие приводит к большим энергетическим затратам при формировании структуры ступеней буфера, что отражается, в частности, в нарушении когерентности сочленения бездислокационного с нижележащим слоем.

Ключевые слова: гетероструктура, метаморфный буфер, сжимающие напряжения, двухстадийный деформационный процесс, энергетические затраты.

DOI: 10.21883/FTP.2019.08.48000.9129

\section{1. Введение}

Одним из наиболее важных конструкционных элементов гетероструктур, используемых в приборах СВЧ электроники (например, в высокочастотном транзистоpe, high electron mobility transistor - НЕMT), является метаморфный буфер (ММБ), расположенный между подложкой и активными слоями приборных структур и предназначенный для демпфирования упругих напряжений, возникающих из-за несовпадения периодов кристаллических решеток подложки и квантовой ямы (КЯ) $[1,2]$. Эффект демпфирования достигается за счет изменяющегося по толщине слоя периода решетки ММБ, что позволяет осуществить подгонку периодов решеток различных конструкционных элементов HЕMТ. В случае гетероструктур с КЯ типа InAlAs/InGaAs/InAlAs изменение периода решетки в ММБ достигается за счет изменения концентрации легирующего элемента, в качестве которого используется индий. Буфер может быть как одноступенчатым (с переменным содержанием In по толщине слоя), так и многоступенчатым. В последнем случае содержание In в каждой ступени ММБ отличается от содержания In в соседних ступенях. Важной особенностью ступенчатого ММБ является способность к формированию бездислокационной области, расположенной, как правило, в верх- нем эпитаксиальном слое системы [3]. Наличие бездислокационной области предотвращает проникновение прорастающих дислокаций в активные слои НЕМТ. В [4] на примере однослойного ММБ с линейным законом изменения концентрации легирующего элемента по толщине буфера было показано, что при образовании бездислокационного слоя в такой системе достигается локальный минимум свободной энергии. Распространение модельного подхода, развитого в [4], на ступенчатые ММБ было дано в [3,5]. В основу этих работ была положена выявленная при изучении структурной релаксации в однослойных гетероструктурах $\operatorname{In}_{x} \mathrm{Ga}_{1-x}$ As закономерность, заключающаяся в существовании обратно пропорциональной зависимости между остаточной упругой деформацией и толщиной эпитаксиального слоя [6,7]. Данная закономерность наблюдается при толщинах 100-800 нм; при превышении критической толщины $\left(\sim 800\right.$ нм для $\left.\operatorname{In}_{x} \mathrm{Ga}_{1-x} \mathrm{As}\right)$ структурная релаксации замедляется, что вызвано деформационным упрочнением, которое в общем случае обусловлено взаимодействием движущихся дислокаций между собой [8]. Эффект деформационного упрочнения приводит к более высоким значениям остаточных упругих деформаций в эпитаксиальном слое (слоях) гетероструктуры и в ряде случаев, как отмечается в [9], может вызывать эффект „вмороженного“ (в слои буфе- 
ра) деформационного поля - увеличение остаточных упругих деформаций не только в области, испытывающей структурную релаксацию, но и в бездислокационном слое.

Принципиальной особенностью ступенчатых ММБ является наличие в них межфазных границ, которые могут существенно изменять характер структурной релаксации. Наличием межфазных границ, например, можно объяснить установленный в [10] экспериментальный факт, что в многослойных тонкопленочных системах критическая толщина эпитаксиального слоя, при которой начинает развиваться эффект деформационного упрочнения, существенно меньше по сравнению с толщиной слоя в однослойной гетероструктуре. Межфазные границы, с одной стороны, являются областями мультипликации дислокаций несоответствия, а с другой, обладают способностью препятствовать их скольжению [11]. Такое свойство межфазных границ способствует скоплению скользящих фрагментов дислокаций несоответствия в приграничной области и, учитывая малые толщины ступеней ММБ (как правило, 100-200 нм), может вызвать эффект межслоевого упрочнения, которое можно рассматривать как частный случай деформационного упрочнения. По своей природе межслоевое упрочнение аналогично зернограничному упрочнению [12], имеющему место в консолидированных металлических нанокристаллах с размером зерна $10-25$ нм [13]. Такой вид упрочнения может привести к возникновению вертикальных напряжений, существованием которых обычно при описании упругонапряженного состояния в слоях многоступенчатых ММБ пренебрегают.

Известно, что в основе современных представлений о формировании упругонапряженного состояния в однослойных гетероструктурах лежит процесс двухосного сжатия [14]. В данной работе с целью более адекватного описания процесса структурной релаксации (в частности для учета влияния эффекта межслоевого упрочнения) предложено использовать более сложные схемы нагружения. Целью данной работы явилось определение энергетических затрат при формировании упругонапряженного состояния в многоступенчатом ММБ в рамках двухстадийного деформационного процесса. Исходные экспериментальные данные о кристаллографических параметрах эпитаксиальных слоев ММБ были получены с помощью построения карт обратного пространства - высокоразрешающего метода рентгеноструктурного анализа, который позволяет учитывать разориентацию эпитаксиальных слоев в пространстве, что присуще гетероэпитаксиальным структурам [15]. Как показано в [16], поправка на эффект пространственной разориентации вносит существенные изменения в координаты неосновных интерференционных максимумов при определении их положения в обратном пространстве. Далее при описании НЕМТ, содержащего ММБ, мы будем использовать аббревиатуру МНЕМТ (metamorphic HEMT).

\section{2. Экспериментальная часть}

\section{1. Выращивание гетероструктуры}

Структура МНЕМТ с активными слоями InAlAs/InGaAs/InAlAs, содержащая пятиступенчатый ММБ, была выращена на стандартной полуизолирующей подложке GaAs c ориентацией (001) методом молекулярно-лучевой эпитаксии на установке RIBER 32P. Мольное содержание In, $X_{\text {In }}$, в активных слоях МНЕМТ было равно 0.39. Толщина первых четырех ступеней ММБ равнялаь 0.1 мкм, величина $X_{\text {In }}$ в них составляла $0.15,0.23,0.29$ и 0.35 . Пятая ступень имела толщину 0.2 мкм с $X_{\text {In }}=0.39$. Такое же мольное содержание In и такую же толщину имел нижний барьерный слой следующий конструкционный элемент МНЕМТ. Рост ММБ происходил при постоянной температуре подложки, равной $380^{\circ} \mathrm{C}$. Нижний барьерный слой МНЕМТ был выращен при более высокой температуре подложки, равной $480^{\circ} \mathrm{C}$. Скорость роста эпитаксиальных слоев равнялась 0.5 мкм $\cdot ч^{-1}$. Перед ростом нижнего барьерного слоя для повышения температуры подложки процесс эпитаксии был остановлен на 5 мин. В процессе роста состав элементов конструкции МНЕМТ контролировался температурой молекулярных источников In, Al, Ga, As и $\mathrm{Si}$ (последний из элементов использовался для $\delta$-легирования) на основе предварительной калибровки температурной зависимости молекулярных потоков. Перед выращиванием ММБ на подложке была сформирована сверхрешетка, на которой был выращен слой из чистого GaAs толщиной 100 нм.

\section{2. Аттестация МНЕMT}

Для аттестации выращенной структуры MHEMT использовали методы вторично-ионной масс-спектрометрии (ВИМС) и просвечивающей электронной микроскопии (ПЭМ). Для проведения анализа методом ВИМС использовали масс-спектрометр IMS-4f фирмы Cameca; при профилировании первичный ионный пучок был сформирован на основе ионов $\mathrm{Cs}^{+}$с энергией 5.5 кэВ. В качестве вторичных ионов регистрировались ионы $\mathrm{GaCs}_{2}^{+}, \mathrm{InCs}_{2}^{+}$и $\mathrm{AlCs}_{2}^{+}$. За величину $X_{\mathrm{In}}$ принимали отношение тока ионов $\mathrm{InCs}_{2}^{+}$к сумме токов ионов $\mathrm{GaCs}_{2}^{+}$, $\mathrm{InCs}_{2}^{+}$и $\mathrm{AlCs}_{2}^{+}$. Учет выхода ионов $\mathrm{GaCs}_{2}^{+}$позволяет максимально снизить влияние матричного эффекта и существенно повысить точность определения величины $X_{\text {In }}$, особенно в области межфазной границы между подложкой и первой ступенью ММБ. Структурная аттестация МНЕМТ была выполнена на микроскопе Jeol JEM 2010 при ускоряющем напряжении 200 кВ.

\section{3. Рентгеновская съемка}

Рентгеновская съемка проводилась в трехосевой геометрии с использованием прецизионного дифрактометpa SmartLab 9kW в пошаговом режиме в излучении меди $K_{\alpha(1)}$ при двух азимутальных углах, 0 и $90^{\circ}$. 

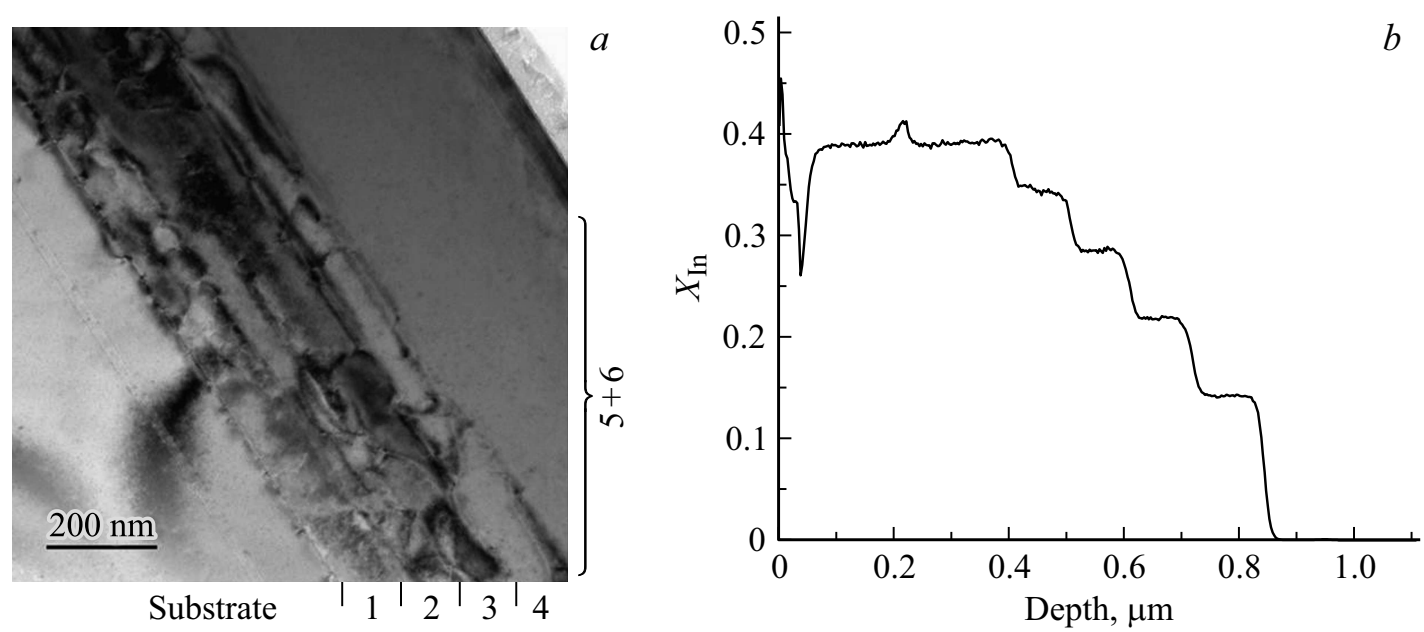

Рис. 1. Результаты аттестации МНЕМТ: светлопольное ПЭМ-изображение поперечного сечения $(a)$ и пространственное распределение мольного содержания In в эпитаксиальных слоях, полученное методом ВИМС $(b)$. Цифры - порядковые номера эпитаксиальных слоев.

В качестве кристалла-анализатора был использован монокристалл $\mathrm{Ge}$ с ориентацией (022). Съемка велась в двух рефлексах, 004 и 224 (в положении скользящего отражения), в режиме $\omega-2 \theta$-сканирования, которое заключается в съемке образца по методу БрэггаБрентано при различных исходных угловых отклонениях подложки от угла Брэгга. Режим $\omega-2 \theta$-сканирования позволяет построить карты обратного пространства, представляющие собой набор линий равной интенсивности дифрагированного рентгеновского излучения, включая области пучностей (неосновных рентгеновских максимумов), с указанием их расположения вдоль осей обратного пространства, [001]) (ось Z) и [110] (ось $Y$ ). За начало координат обратного пространства принимали основной рентгеновский максимум, соответствующий подложке. Координаты неосновных рентгеновских максимумов (т.е. значения векторов $q_{y}$ и $q_{z}$, являющихся отклонениями от основного рентгеновского максимума) определяли путем нахождения точки обратного пространства с максимальным значением интенсивности дифрагированного рентгеновского излучения, используя для этой цели специальную опцию компьютерной программы Origin 15.

\section{3. Экспериментальные результаты}

Общий вид гетероструктуры (светлопольное ПЭМизображение ее поперечного сечения), а также пространственное распределение мольной доли $X_{\text {In }}$ в эпитаксиальных слоях МНЕМТ приведены на рис. 1. Видно, что в нижних 4-х ступенях ММБ наблюдается скопление дислокаций, в то время как 5-я ступень ММБ и прилегающий к ней нижний барьерный слой от дислокаций свободны. В структурном отношении финальные эпитаксиальные слои (слои 5 и 6) являются единым конструкционным элементом, который ввиду отсутствия прорастающих дислокаций можно рассматривать как бездислокационную область. Далее по тексту мы будем рассматривать 5-ю ступень ММБ и нижний барьерный слой как объединенный 5-й слой толщиной 0.4 мкм. Из данных ВИМС следует, что величина $X_{\text {In }}$ в эпитаксиальных слоях МНЕМТ совпадает с задаваемыми в процессе роста концентрациями In, а глубина залегания In в пространстве соответствует задаваемым толщинам эпитаксиальных слоев.

На рис. 2 показаны карты обратного пространства (отражения 004 и 224) для двух азимутальных углов, 0 и $90^{\circ}$. На них видны пять неосновных рентгеновских максимумов, которые в соответствии с ростом величины $\left|q_{z}\right|$ можно приписать слоям 1, 2, 3, 4 и 5(6). Наличие одного (пятого по счету) сильного рефлекса свидетельствует о том, что слои 5 и 6 являются в структурном отношении одинаковыми, что согласуется с результатами ПЭМ-исследования. Карты обратного пространства позволяют определить так называемые „полные“ (относительно подложки $\mathrm{GaAs}$ ) деформации $\varepsilon_{\perp}$ и $\varepsilon_{\|}$каждого из эпитаксиальных слоев: $\varepsilon_{\perp}$ вдоль кристаллографической оси $[001]\left(\varepsilon_{\perp}=\left[\left(a_{\perp}-a_{s}\right) / a_{s}\right]_{\langle 100\rangle}\right)$ и $\varepsilon_{\|}$вдоль кристаллографических осей [110] и [110] $\left(\varepsilon_{\|}=\left[\left(a_{\|}-a_{s} / a_{s}\right]_{\langle 110\rangle}\right)\right.$, где $a_{\perp}$ и $a_{\|}-$вертикальный и латеральный периоды решетки слоя в соответствующих кристаллографических направлениях, $a_{s}-$ период решетки подложки. Необходимость определения двух значений $\varepsilon_{[110]}$ и $\varepsilon_{[1 \overline{1} 0]}$ обусловлена наличием в химических соединениях GaAs, InAs и AlAs двух типов дислокаций, так называемых $\alpha$ - и $\beta$-дислокаций [17], которые ответственны за релаксационные процессы в двух взаимно перпендикулярных направлениях [110] и [1ㅣㅣ. Эти направления в указанных веществах неэквивалентны, так как вектор Бюргерса в них связан с подрешетками, образованными различными сортами атомов. Процедура определения величин $\varepsilon_{\perp}$ и $\varepsilon_{\|}$на основе соответствующих карт обратного пространства 

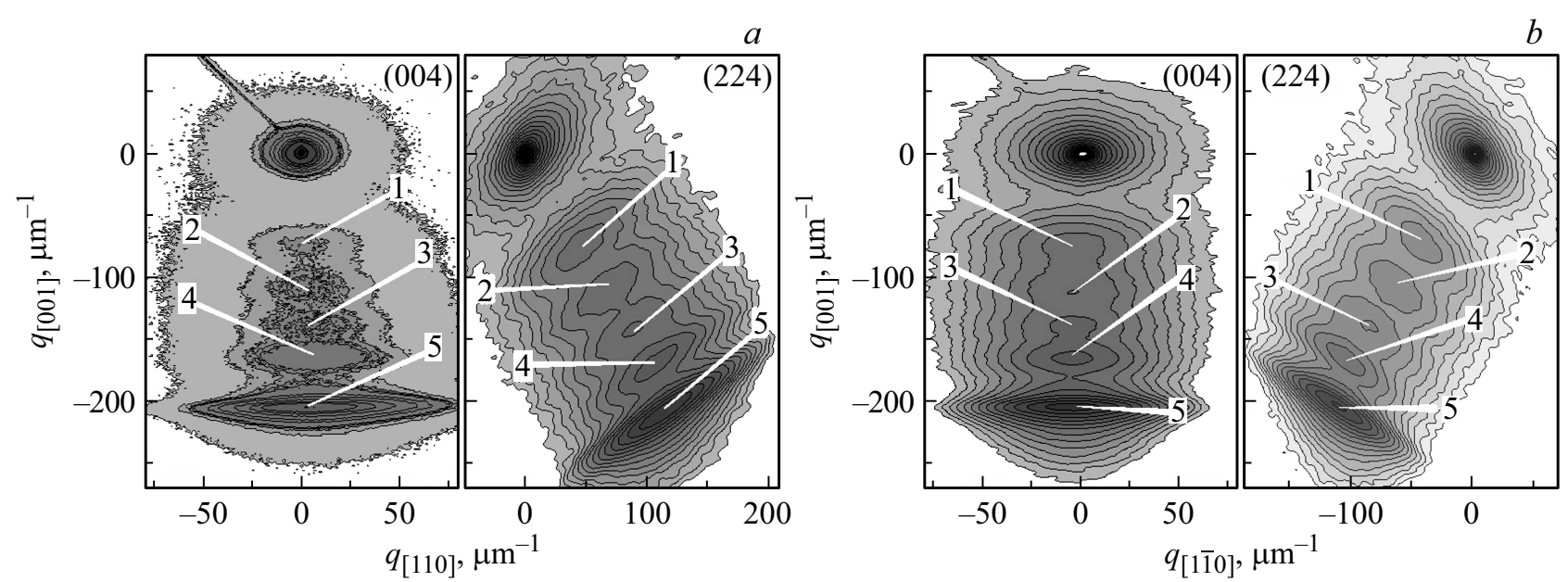

Рис. 2. Карты обратного пространства, полученные на основе отражений 004 и 224 , для двух азимутальных углов $0^{\circ}(a)$ и $90^{\circ}(b)$. Указаны порядковые номера эпитаксиальных слоев, ответственных за появление данного рентгеновского максимума.

описана в [18]. Для определения компонентов тензора упругой деформации $e_{i i}$ и $e_{i j}$ необходимо перейти от $\varepsilon_{[110]}$ и $\varepsilon_{[1 \overline{10}]}$ к $\varepsilon_{11}$ и $\varepsilon_{22}$ - диагональным компонентам тензора полных упругих деформаций, записанных в главных кристаллографических осях. Такой переход достигается вращением системы декартовых координат вокруг оси [001] на угол $45^{\circ}$. Компоненты $\varepsilon_{11}$ и $\varepsilon_{22}$, а также недиагональный компонент $\varepsilon_{12}$ будут равны

$$
\begin{gathered}
\varepsilon_{11}=\varepsilon_{22}=\frac{\varepsilon_{[110]}+\varepsilon_{[1 \overline{1} 0]}}{2}, \\
\varepsilon_{12}=\frac{\varepsilon_{[1 \overline{1} 0]}-\varepsilon_{[110]}}{2} .
\end{gathered}
$$

Планарная геометрия изучаемого объекта не позволяет определить недиагональные компоненты $\varepsilon_{13}, \varepsilon_{23}$, и в данной работе их полагали равными нулю. Такое ограничение является стандартным и широко используемым при изучении релаксационных процессов в однослойных гетероструктурах на основе GaAs $[6,7,19]$. За $\varepsilon_{33}$ принимали усредненное значение $\varepsilon_{\perp}$ по двум азимутальным углам.

Упругие деформации $e_{i j}$ (отнесенные к равновесному состоянию вещества) в обобщенном виде (включающем случай $i=j$ ) определяются выражением

$$
e_{i j}=\frac{\varepsilon_{i j}-\delta_{i j} \varepsilon_{0}^{V}}{1+\varepsilon_{0}^{V}}
$$

где $\delta_{i j}$ - символ Кронекера, $\varepsilon_{0}^{V}$ - параметр рассогласования, равный $\left(a_{R}-a_{s}\right) / a_{s}\left(a_{R}-\right.$ период полностью релаксированной решетки данного эпитаксиального слоя, рассчитанный в соответствии с законом Вегарда), а напряжения вдоль главных кристаллографических осей $\sigma_{33}$ и $\sigma_{11}$ - выражениями

$$
\sigma_{33}=\frac{\left(S_{11}+S_{12}\right) e_{33}-2 S_{12} e_{11}}{\left(S_{11}+S_{12}\right) S_{11}-2 S_{12}^{2}},
$$

$$
\sigma_{11}=\frac{e_{11}-S_{12} \sigma_{33}}{S_{11}+S_{12}}
$$

Величина $\sigma_{12}$ рассчитывалась в соответствии с выражением

$$
\sigma_{12}=2 \frac{1}{S_{44}} e_{12}
$$

В выражениях (4), (5) и (6) символами $S_{11}, S_{12}$ и $S_{44}$ обозначены коэффициенты упругой податливости. При обработке экспериментальных данных тройные твердые растворы $\operatorname{In}_{x} \mathrm{Al}_{1-x}$ As рассматривались как двойные растворы соединений AlAs и InAs c переменным составом по In и Al. Значения $S_{11}, S_{12}$ и $S_{44}$ рассчитывались на основе коэффициентов упругой жесткости, $C_{11}, C_{12}$ и $C_{44}$, которые были взяты из [20]. Необходимый для расчета значений $\varepsilon_{11}, \varepsilon_{33}$ и $\varepsilon_{12}$ период решетки GaAs, a также периоды решеток AlAs и InAs, необходимые для расчета $\varepsilon_{0}^{V}$, были взяты из [21]. Для тройных растворов $\operatorname{In}_{x} \mathrm{Al}_{1-x} \mathrm{As}$ значения $C_{11}, C_{12}$ и $C_{44}$ были рассчитаны на основе закона Вегарда. В соответствии с результатами, полученными методом ВИМС, за величину $X_{\text {In }}$ принимали значение, задаваемое в процессе изготовления MHEMT. Результаты рентгеноструктурного анализа, а также параметры упругонапряженного состояния многослойной тонкопленочной системы - 4-е первые ступени ММБ и объединенный 5-й слой - приведены в табл. 1.

Значения $\varepsilon_{11}$ и $\varepsilon_{33} \quad\left(\varepsilon_{33}>\varepsilon_{11}\right)$ свидетельствуют о возникновении тетрагональности в слоях МНЕМТ, что типично для многослойных гетероструктур, выращенных на основе материалов с решетками кубической сингонии [22]. В табл. 1 приведено также изменение свободной энергии $\Delta F_{v}$ (на единицу объема), вызванное деформационным воздействием, для всех ступеней ММБ. Расчет велся в соответствии с выражением [23]

$$
\begin{aligned}
& \Delta F_{v}=\frac{1}{2} C_{11}\left(e_{11}^{2}+e_{22}^{2}+e_{33}^{2}\right) \\
& +C_{12}\left(e_{11} e_{22}+e_{11} e_{33}+e_{22} e_{33}\right)+2 C_{44}\left(e_{12}^{2}+e_{13}^{2}+e_{23}^{2}\right),
\end{aligned}
$$


Таблица 1. Результаты рентгеноструктурного анализа и параметры упругонапряженного состояния эпитаксиальных слоев MHEMT, рассчитанные в соответствии с законом Гука

\begin{tabular}{l|c|c|l|l|l}
\hline \multicolumn{1}{c|}{ Параметры } & Слой 1 & Слой 2 & Слой 3 & Слой 4 & Слой 5 \\
\hline$X_{\mathrm{In}}$ & 0.15 & 0.23 & 0.29 & 0.35 & 0.39 \\
$\varepsilon_{0}^{V}, \times 10^{-3}$ & 12.10 & 17.71 & 21.92 & 26.12 & 28.92 \\
$\varepsilon_{[110]}, \times 10^{-3}$ & 8.52 & 13.01 & 17.06 & 21.78 & 22.19 \\
$\varepsilon_{[110]}, \times 10^{-3}$ & 8.07 & 12.63 & 16.65 & 21.43 & 21.79 \\
$\varepsilon_{11}, \times 10^{-3}$ & 8.295 & 12.82 & 16.855 & 21.605 & 21.99 \\
$\varepsilon_{\perp}\left(0^{\circ}\right), \times 10^{-3}$ & 10.77 & 15.90 & 20.11 & 23.85 & 29.89 \\
$\varepsilon_{\perp}\left(90^{\circ}\right), \times 10^{-3}$ & 10.77 & 16.00 & 20.09 & 23.93 & 29.79 \\
$\varepsilon_{33}, \times 10^{-3}$ & 10.77 & 15.95 & 20.10 & 23.89 & 29.84 \\
$\varepsilon_{12}, \times 10^{4}$ & -2.25 & -1.90 & -2.05 & -1.75 & -2.00 \\
$e_{11}, \times 10^{-3}$ & -3.76 & -4.80 & -4.95 & -4.40 & -6.74 \\
$e_{33}, \times 10^{-3}$ & -1.32 & -1.73 & -1.78 & -2.17 & 0.89 \\
$e_{12}, \times 10^{-4}$ & -2.22 & -1.87 & -2.01 & -1.71 & -1.95 \\
$\sigma_{11}, \mathrm{MПа}$ & -712.0 & -891.5 & -902.7 & -819.7 & -1019.4 \\
$\sigma_{33}, \mathrm{MПа}$ & -566.7 & -714.9 & -725.2 & -698.5 & -612.2 \\
$\sigma_{12}, \mathrm{MПа}$ & -24.9 & -20.3 & -21.4 & -17.8 & -20.0 \\
$\Delta F_{v}$, Дж/см${ }^{3}$ & 3.06 & 4.90 & 5.12 & 4.37 & 6.60
\end{tabular}

справедливым для кристаллов кубической сингонии. Как и следовало ожидать, наибольшее значение $\Delta F_{v}$ было зафиксировано для бездислокационного слоя.

\section{4. Обсуждение результатов}

\section{1. Модельное описание деформационного поля в ступенях метаморфного буфера}

При анализе упругонапряженного состояния эпитаксиальных слоев в многослойных МНЕМТ большую роль играет параметр рассогласования $\varepsilon_{0}^{s l}$, рассчитываемый на основании закона Гука для одиночного эпитаксиального слоя со свободной поверхностью при его деформации по схеме двухосного сжатия [24]. Для кристаллов кубической сингонии выражение для расчета величины $\varepsilon_{0}^{s l}$ имеет вид

$$
\varepsilon_{0}^{s l}=\varepsilon_{33}^{s l}-\frac{2 C_{12}}{C_{11}+2 C_{12}}\left(\varepsilon_{33}^{s l}-\varepsilon_{11}^{s l}\right),
$$

где $\varepsilon_{i i}^{s l}$ - диагональные компоненты тензора полных деформаций, определяемые экспериментально. Расчеты показали, что для всех ступеней ММБ выполняется неравенство $\varepsilon_{a}^{s l}<\varepsilon_{0}^{V}$, где $\varepsilon_{a}^{s l}-$ кажущийся параметр рассогласования, рассчитываемый на основании выражения (8) и приведенных в табл. 1 экспериментальных значений $\varepsilon_{11}$ и $\varepsilon_{33}$. Неравенство $\varepsilon_{a}^{s l}<\varepsilon_{0}^{V}$ свидетельствует о наличии в ступенях ММБ сжимающих вертикальных напряжений $\sigma_{33}\left(\sigma_{33} \neq 0\right)$. Данный экспериментальный факт позволяет предположить, что в многослойной системе наряду с процессом двухосного сжатия протекает также процесс всестороннего сжатия, причиной которого является эффект межслоевого упрочнения (множество плоскостей семейства $\{111\}$ в кубических кристаллах способствует этому процессу).

Дадим формальное описание упругонапряженного состояния эпитаксиальных слоев ММБ в условиях межслоевого упрочнения. В кристаллах кубической сингонии процесс всестороннего сжатия вдоль главных кристаллографических осей (случай, соответствующий исследуемой структуре МНЕМТ) является аналогом процесса сжатия изотропных материалов в условиях гидростатического давления. При этом относительное изменение элементарного объема $\Delta V / V$ описывается выражением

$$
\frac{\Delta V}{V}=\frac{\sigma_{b c}}{\beta},
$$

где $\beta$ - объемный модуль упругости (для рассматриваемого нами случая $\left.\beta=\left(C_{11}+2 C_{12}\right) / 3\right)$ и $\sigma_{b c}-$ сжимающие напряжения вдоль главных кристаллографических осей. Поскольку в кристаллах кубической сингонии при продольных деформациях вдоль главных осей $\langle 100\rangle$ коэффициент Пуассона не зависит от латеральных кристаллографических направлений [25], выражение (9) может быть использовано для расчета периода решетки, испытывающей всестороннее сжатие, $a^{b c}$. Величину $a_{b c}$ можно представить в виде параметра рассогласования $\varepsilon_{0}^{b c}\left(\varepsilon_{0}^{b c}=\left(a^{b c}-a_{s}\right) / a_{s}\right)$, который описывается выражением

$$
\varepsilon_{0}^{b c}=\left(1+\varepsilon_{0}^{V}\right)\left(1-\left|\frac{\sigma_{b c}}{\beta}\right|\right)^{1 / 3}-1 .
$$

Расчет показывает, что при $\sigma_{b c}=\sigma_{33}$ расхождение между величинами $\varepsilon_{0}^{b c}$ и $\varepsilon_{a}^{s l}$ крайне мало́ и не превышает для различных слоев $0.04-0.1 \%$. Такое совпадение значений параметров рассогласования $\varepsilon_{0}^{b c}$ и $\varepsilon_{a}^{s l}$, соответствующих различным схемам деформации - всестороннему $\left(\varepsilon_{0}^{b c}\right)$ и двухосному $\left(\varepsilon_{a}^{s l}\right)$ сжатию, - свидетельствует о том, что финальное упругонапряженное состояние эпитаксиальных слоев МНЕМТ, зафиксированное процессом структурной релаксации, можно промоделировать двухстадийным деформационным процессом, состоящим из стадии всестороннего сжатия и последующей стадии двухосного сжатия (при этом поведение нагружаемого эпитаксиального слоя соответствует поведению слоя со свободной поверхностью).

На рис. 3 дана визуализация деформационного процесса, протекающего по двум возможным схемам нагружения материала, соответствующим одностадийному (рис. 3, a) и двухстадийному (рис. $3, b$ ) деформационным процессам. Визуализация была получена в результате компьютерного моделирования, выполненного с помощью программного пакета Comsol multiphysics 5.2 при использовании расчетного модуля Solid mechanics на основе применения метода конечных элементов [26]. В качестве объекта моделирования был использован куб единичного объема с гранями типа $\{100\}$ и химическим составом, совпадающим с химическим составом ступеней ММБ. Данный объект размещался на подложке 

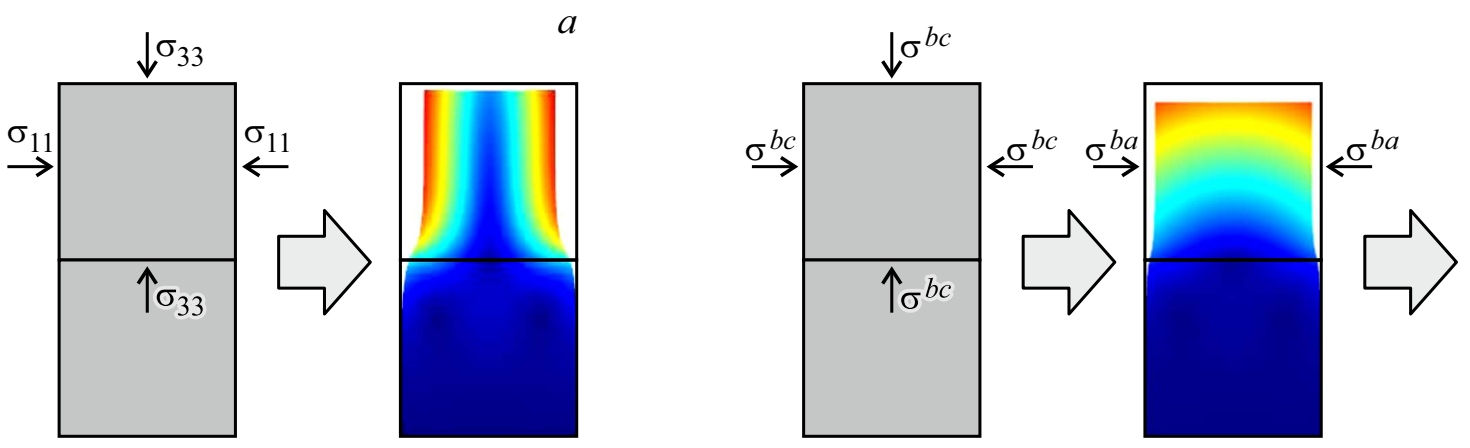

$b$

Рис. 3. Визуализация процесса деформации при одновременном воздействии на эпитаксиальный слой латеральных $\left(\sigma_{11}\right)$ и вертикальных $\left(\sigma_{33}\right)$ напряжений сжатия $(a)$ и при последовательном воздействии напряжений всестороннего $\left(\sigma^{b c}=\sigma_{33}\right)$ и двухосного $\left(\sigma^{b a}=\sigma_{11}-\sigma_{33}\right)$ сжатия $(b)$. Визуализация выполнена для бездислокационного слоя.

(в качестве которой мог выступать и нижележащий слой), имеющей также единичный объем и соответствующий химический состав. Объекту моделирования приписывались соответствующие его химическому составу (в зависимости от номера ступени ММБ) коэффициенты жесткости и коэффициент Пуассона. Величина сжимающих напряжений в обоих случаях соответствовала экспериментальным данным. Недиагональный компонент тензора напряжений $\sigma_{12}$ при моделировании в обоих случаях не учитывали. Градиентом цвета на рис. 3 показана величина смещения каждого узла моделируемого объекта (число задаваемых узлов равнялось $1.2 \cdot 10^{4}$ ). Видно, что смещение узлов объекта компьютерного моделирования при разных схемах нагружения - одностадийной деформации и двухстадийного деформационного процесса одно и то же, что соответствует одному и тому же финальному состоянию материала. Идентичность состояний, возникающих в результате прямого воздействия на объект моделирования напряжений $\sigma_{11}, \sigma_{33}$ и при проведении двухстадийного деформационного процесса, свидетельствует об адекватности применения последнего случая для описания упругонапряженного состояния ступеней ММБ. Заметим, что энергетические затраты, рассчитанные методом компьютерного моделирования по первой и второй схемам нагружения ступеней ММБ, были равны и составляли для разных ступеней ММБ 3.8-6.6 Дж/ $\mathrm{cm}^{3}$, что достаточно близко к результатам аналитического расчета на основании выражения (7).

\section{2. Энергетические затраты и структурное состояние ступеней метаморфного буфера}

В случае двухстадийного деформационного процесса, лежащего в основе рассматриваемого в данной работе модельного подхода для описания упругонапряженного состояния в ступенях ММБ, суммарную упругую деформацию $e_{i i}^{\text {mod }}$ можно представить как сумму деформации всестороннего сжатия $e_{0}^{b c}$ и латеральной (или вертикальной) деформации $u_{i i}^{\text {mod }}$, возникающей при двухосном сжатии слоя со свободной поверхностью:

$$
e_{i i}^{\bmod }=e_{0}^{b c}+u_{i i}^{\bmod } .
$$

Величины $e_{0}^{b c}$ и $u_{i i}^{\text {mod }}$ связаны с параметрами рассогласования $\varepsilon_{0}^{b c}$ и $\varepsilon_{0}^{s l}$ следующими соотношениями:

$$
e_{0}^{b c}=\frac{\varepsilon_{0}^{b c}-\varepsilon_{0}^{V}}{1+\varepsilon_{0}^{V}}
$$

и

$$
u_{i i}^{\bmod }=\frac{\varepsilon_{i i}-\varepsilon_{a}^{s l}}{1+\varepsilon_{a}^{s l}} .
$$

Модельные значения остаточных упругих деформаций $e_{0}^{b c}, u_{i i}^{\bmod }$ и $e_{i i}^{\bmod }$ приведены в табл. 2. Попарное сравнение величин $e_{i i}^{\bmod }$ и $e_{i i}$ показывает, что они близки и практически совпадают друг с другом.

Использование в качестве основных характеристик деформационного поля ступенчатого ММБ деформаций $e_{0}^{b c}$ и $u_{i i}^{\bmod }$ позволяет выделить из общих энергетических затрат, характеризуемых величиной $\Delta F_{v}$, затраты, связанные с работой деформации каждой из стадий двухстадийного деформационного процесса. Соответствующее аналитическое выражение было получено преобразованием выражения (7) путем замены $e_{i i}$ на $e_{i i}^{\bmod }$ и с учетом соотношения

$$
\frac{u_{33}^{\bmod }}{u_{11}^{\bmod }}=-\frac{2 C_{12}}{C_{11}},
$$

справедливого для слоя со свободной поверхностью, подвергнутого двухосному сжатию. Конечное выражение

Таблица 2. Модельные значения остаточных упругих деформаций в эпитаксиальных слоях МНЕМТ

\begin{tabular}{l|l|l|l|l|l}
\hline Параметры & Слой 1 & Слой 2 & Слой 3 & Слой 4 & Слой 5 \\
\hline$e_{0}^{b c}, \times 10^{-3}$ & -2.52 & -3.25 & -3.36 & -3.29 & -2.92 \\
$u_{11}^{\bmod }, \times 10^{-3}$ & -1.25 & -1.56 & -1.61 & -1.12 & -3.84 \\
$u_{33}^{\bmod }, \times 10^{-3}$ & 1.20 & 1.52 & 1.58 & 1.09 & 3.81 \\
$e_{11}^{\bmod }, \times 10^{-3}$ & -3.77 & -4.81 & -4.97 & -4.41 & -6.76 \\
$e_{33}^{\bmod }, \times 10^{-3}$ & -1.32 & -1.73 & -1.78 & -2.20 & 0.89
\end{tabular}



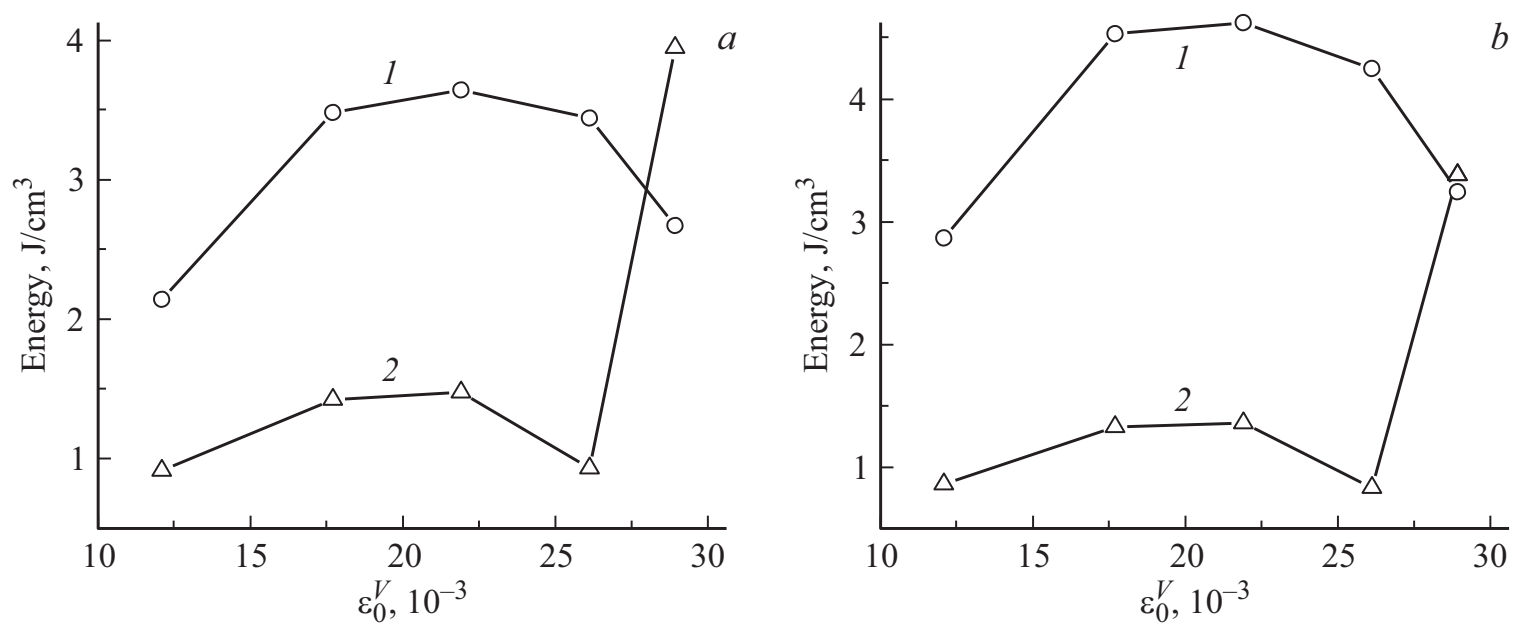

Рис. 4. Пространственные распределения энергетических затрат, построенные в виде зависимости от $\varepsilon_{0}^{V}$, при проведении первой (1) и второй (2) стадий деформационного процесса. Распределения получены в результате аналитического расчета $(a)$ и проведения компьютерного эксперимента $(b)$.

имеет вид

$$
\Delta F_{v}^{\mathrm{mod}}=\frac{1}{2} \beta \xi^{2}+B\left(u_{11}^{\bmod }\right)^{2}+2 \beta \frac{C_{11}-C_{12}}{C_{11}} \xi u_{11}^{\bmod }
$$

где $\xi=3 e_{0}^{b c}$ и $B=\left(C_{11}+2 C_{12}\right)\left(C_{11}-C_{12}\right) / C_{11}$. При выводе выражения (15) недиагональным компонентом тензора упругой деформации $e_{12}$ пренебрегли. Расчеты показывают, что замена $e_{i i}$ на $e_{i i}^{\text {mod }}$ приводит к расхождению между $\Delta F_{v}^{\text {mod }}$ и $\Delta F_{v}$ не более чем $0.2 \%$, что является подтверждением правильности используемого модельного описания. Первое и второе слагаемые в выражении (15) описывают энергетические затраты при всестороннем $\left(\Delta F_{v}^{b c}\right)$ и двухосном $\left(\Delta F_{v}^{b a}\right)$ сжатии, а третий член является энергетической добавкой $\left(\Delta F_{v}^{\text {sup }}\right)$ к работе двухосного сжатия (и к соответствующему этой работе изменению свободной энергии $\left.\Delta F_{v}^{b a}\right)$, появление которой отражает специфику второй стадии деформационного процесса в условиях предварительного воздействия всестороннего сжатия. Наряду с вышеперечисленными символами мы будем также использовать символы $\Delta F_{v}^{(1)}$ и $\Delta F_{v}^{(2)}$ для обозначения энергетических затрат при проведении первой и второй стадий деформационного процесса.

На основании выражения (15) были построены пространственные (послойные) распределения энергетических затрат для каждой из стадий двухстадийного деформационного процесса, что позволяет выявить их связь со структурой каждой ступени ММБ. Соответствующие пространственные распределения, построенные от параметра рассогласования $\varepsilon_{0}^{V}$, приведены на рис. 4, $a$. Видно, что для первых 4 ступеней пространственные распределения $\Delta F_{v}^{(1)}\left(\varepsilon_{0}^{V}\right)$ и $\Delta F_{v}^{(2)}\left(\varepsilon_{0}^{V}\right)$ подобны; разница между ними заключается лишь в значительно бо́льших энергетических затратах при проведении всестороннего сжатия по сравнению с затратами при второй стадии деформационного процесса. При переходе к 5-у без- дислокационному слою характер пространственных зависимостей $\Delta F_{v}^{(1)}\left(\varepsilon_{0}^{V}\right)$ и $\Delta F_{v}^{(2)}\left(\varepsilon_{0}^{V}\right)$ становится противоположным. Переход характеризуется снижением $\Delta F_{v}^{(1)}$ и резким ростом $\Delta F_{v}^{(2)}$. Аналогичные пространственные распределения энергетических затрат для первой и второй стадий деформационного процесса были получены в результате проведения компьютерного эксперимента (рис. $4, b)$. Характер пространственного распределения $\Delta F_{v}^{(2)}\left(\varepsilon_{0}^{V}\right)$ в целом соответствует модельному описанию формирования бездислокационного слоя (бездислокационной области) в ступенчатом ММБ, предложенному в [3], однако величина $\Delta F_{v}^{(2)}\left(3.93\right.$ Дж/см ${ }^{3}$ при аналитическом расчете и 3.38 Дж/см ${ }^{3}$ в компьютерном эксперименте), характеризующая образование бездислокационного слоя, существенно превышает соответствующую энергетическую характеристику $\left(0.5\right.$ Дж/см $\left.{ }^{3}\right)$, рассчитанную по схеме, предложенной в [3], для ступенчатого ММБ аналогичной конструкции. В предложенном в [3] подходе лежит предположение, что в нижних ступенях ММБ происходит полная структурная релаксация, а деформация бездислокационного слоя контролируется феноменологической константой, которая фигурирует при описании релаксационных процессов в однослойных гетероструктурах [6,7]. Причина расхождения между экспериментальными значениями энергетических затрат для второй стадии деформационного процесса и соответствующей величиной, рассчитанной по методике, изложенной в [3], вызвана влиянием на процесс структурной релаксации эффекта межслоевого упрочнения. Это влияние приводит не только к прямому энергетическому вкладу всестороннего сжатия в общий баланс энергии, расходуемой при формировании упругонапряженного состояния ступеней ММБ, но и к увеличению энергетических затрат при проведении второй стадии деформационного процесса - двухосного сжатия. Что же касается прямых энергетических затрат, 

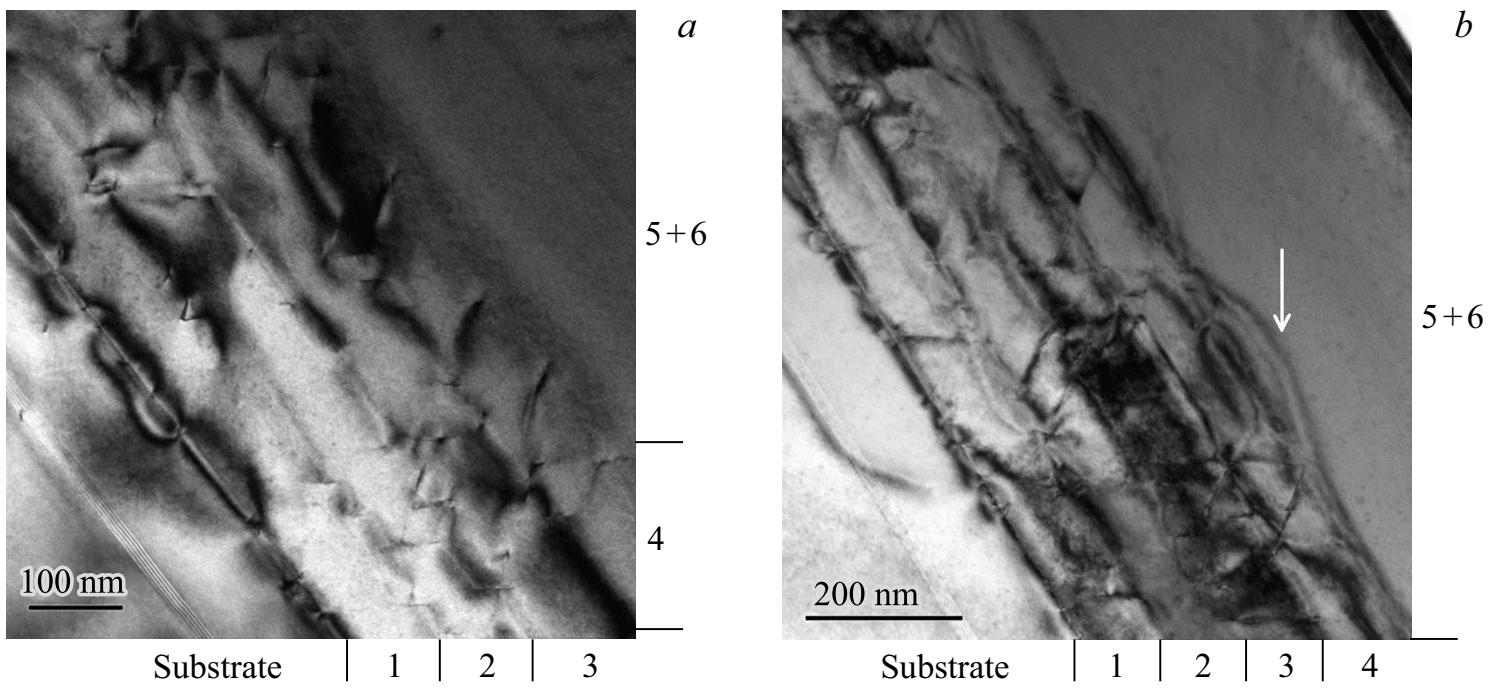

Рис. 5. Структурные фрагменты, характеризующие различный характер сочленения между бездислокационным и нижележащим слоями с образованием когерентного сочленения $(a)$ и некогерентной межфазной границы $(b)$. Стрелкой $(b)$ отмечена дислокационная полупетля, прижатая силами всестороннего сжатия к области межфазной границы.

связанных непосредственно со всесторонним сжатием, то, учитывая характер воздействия всестороннего сжатия на материальный объект в кристаллах кубической сингонии, можно предположить, что это влияние сказывается в первую очередь на характере сочленения ступеней ММБ, в частности на характере сочленения бездислокационного и нижележащего слоев.

Важным структурным параметром ММБ является фактор слоевого зацепления $f_{i}(i-$ номер слоя $)$, определяемый как

$$
f_{i}=\frac{a_{\|}^{i}-a_{\|}^{i-1}}{a_{\|}^{i-1}}
$$

и позволяющий путем сопоставления латеральных периодов двух смежных слоев выявить роль межслоевого упругого взаимодействия в формировании упругонапряженного состояния ММБ как единого целого. Наиболее сильное влияние межслоевое упругое взаимодействие оказывает на формирование бездислокационного слоя. Согласно [4], сочленение бездислокационного слоя с нижележащим релаксированным слоем должно быть когерентным, при этом фактор зацепления бездислокационного слоя $f_{d f l} \rightarrow 0$. В нашем случае экспериментальная величина $f_{5}$ равна $3.8 \cdot 10^{-4}$. Несовпадение значений $f_{5}$ и $f_{d f l}\left(f_{5}>f_{d f l}\right)$ вызвано несовпадением значений $\Delta F_{v}^{(2)}$ для бездислокационного и нижележащего слоев, которое обусловлено в первую очередь несовпадением деформаций всестороннего сжатия $e_{0}^{b c}$ для этих ступеней ММБ.

Экспериментально установленное значение $f_{5}$ отражает факт сочленения бездислокационного слоя через образование некогерентной межфазной границы (рис. $1, a$ ). На рис. 5 показаны результаты более детального выполненного методом ПЭМ исследования характера сочленения бездислокационного и нижележащего слоев. Видно, что в области сочленения имеются участки как с когерентным сочленением (рис. 5, $a$ ), так и с некогерентной межфазной границей (рис. 5, b), вблизи которой в ряде случаев в бездислокационном слое располагалась дислокационная полупетля. Появление дислокационной полупетли отражает процесс генерации дислокации несоответствия на межфазной границе между бездислокационным и нижележащим слоями. Однако число участков сочленения с расположенной вблизи интерфейса дислокационной полупетлей сравнительно невелико, а способность дислокационной полупетли к скольжению в бездислокационном слое снижена [4], что в целом обеспечивает высокую степень его кристалличности. Увеличение толщины последней (5-й ступени) ММБ (прием, используемый при выращивании исследуемой МНЕМТ) обеспечивает гарантию непроникновения скользящих фрагментов дислокаций несоответствия в активные слои приборных структур.

\section{5. Заключение}

Обнаружено, что в многослойной тонкопленочной системе, представляющей собой гетероструктуру с пятиступенчатым метаморфным буфером с толщинами слоев 100-200 нм, наряду с латеральными сжимающими упругими деформациями, появление которых типично при метаморфном эпитаксиальном росте, наблюдаются также и вертикальные сжимающие упругие деформации, связанные с эффектом межслоевого упрочнения. Выполнено моделирование упругонапряженного состояния слоев гетероструктуры, основанное на представлении о протекании в системе двухстадийного деформационного процесса: всестороннего (первая стадия) и двухосного (вторая стадия) сжатия. Показано, что эффект межслоевого упрочнения изменяет структурное состояние 
эпитаксиальных слоев, в результате чего кристаллическая решетка каждого эпитаксиального слоя находится в состоянии всестороннего сжатия, образуя при этом квазиячейку, обладающую свойством слоя со свободной поверхностью. Эффект межслоевого упрочнения приводит к бо́льшим энергетическим затратам при формировании бездислокационного слоя по сравнению с аналогичными затратами в системе, в которой релаксационные процессы контролируются только влиянием подложки, что изменяет характер сочленения этого слоя с нижележащим слоем.

\section{Финансирование работы}

Работа выполнена в рамках Государственного задания на 2019 год № 075-00816-19-00 от 27.12.2018 г. для ИСВЧПЭ РАН.

\section{Конфликт интересов}

Конфликт интересов у авторов отсутствует.

\section{Список литературы}

[1] T. Kujofsa, J.E. Ayers. Int. J. High Speed Electron. Syst., 24, 1520009 (2015).

[2] А.С. Бугаев, Г.Б. Галиев, П.П. Мальцев, С.С. Пушкарев, Ю.В. Федоров. НМСТ, № 10 (147), 14 (2012).

[3] D.J. Dunstan. Phil. Mag. A, 73, 1323 (1996).

[4] J. Tersoff. Appl. Phys. Lett., 62, 693 (1993).

[5] R. Beanland, D.J. Dunstan, P.J. Goodhew. Adv. Phys., 45, 87 (1996).

[6] D.J. Dunstan, P. Kidd, L.K. Howard, R.H. Dixon. Appl. Phys. Lett., 59, 3390 (1991).

[7] D.J. Dunstan, P. Kidd, P.E. Fewster, N.L. Andrew, R. Grey, J.P.R. David, L. Gonzalez, Y. Gonzalez, A. Sacedon, F. Gonzalez-Sanz. Appl. Phys. Lett., 65, 839 (1994).

[8] B.W. Dodson. J. Appl. Phys., 53, 37 (1988).

[9] F. Romanato, E. Napolitani, A. Carnera, A.V. Drigo, L. Lazzarini, G. Salviati, C. Ferrari, A. Bosacchi, S. Franchi. J. Appl. Phys., 86, 4748 (1999).

[10] D. Gonzalez, D. Araujo, G. Aragon, R. Garcia. Appl. Phys. Lett., 71, 3099 (1997).

[11] L.B. Freund, J.C. Ramirez, A.F. Bower. Mater. Res. Soc. Symp. Proc., 160, 47 (1990).

[12] А.В. Нохрин, В.Н. Чувильдеев, В.И. Копылов, Ю.Г. Лопатин, О.Э. Пирожникова, Н.В. Сахаров, А.В. Пискунов, Н.А. Козлова. Вестн. Нижегородского ун-та им. Н.И. Лобачевского, № 5 (2), 142 (2010).

[13] А.И. Гусев. УФН, 168 (1), 55 (1998).

[14] J.E. Ayers. Heteroepitaxy of semiconductors. Theory, growth, and characterization (Roca Raton-London-N. Y., Taylor and Francis Group, 2007) Ch. 5, p. 164

[15] J.E. Ayers, S.K. Ghandhi, L.J. Schowalter. J. Cryst. Growth, 113, 430 (1991).

[16] А.Н. Алешин, А.С. Бугаев, М.А. Ермакова, О.А. Рубан. ФТП, 49, 1065 (2015).

[17] G. Feuillet, D. Cherns. Mater. Sci. Forum, 10-12, 803 (1986).

[18] А.Н. Алешин, А.С. Бугаев, М.А. Ермакова, О.А. Рубан. Кристаллография, 61, 300 (2016).
[19] D.J. Dunstan, P. Kidd, R. Beanland, A. Sacedon, E. Calleja, L. Gonzalez, Y. Gonzalez, F.J. Pacheco. Mater. Sci. Technol., 12, 181 (1996).

[20] K.N. Tu, J.W. Mayer, L.C. Feldman. Electronic thin film science. For electrical engineers and materials scientists (N.Y., Macmillan Publishing Company, 1992) Appendix E, p. 411.

21] С.С. Стрельченко, В.В. Лебедев. Соединения $A_{3} B_{5}$. Справочник (М., Металлургия, 1984) с. 50.

[22] J.E. Ayers. Heteroepitaxy of semiconductors. Theory, growth, and characterization (Roca Raton-London-N. Y., Taylor and Francis Group, 2007) chap. 2, p. 30.

[23] Л.Д. Ландау, Е.М. Лифшиц. Теоретическая физика. T. VII. Теория упругости (М., Физматлит, 2003) гл. 1, с. 58.

[24] Ю.П. Хапачев, Ф.Н. Чуховский. Кристаллография, 34, 776 (1989).

[25] A. Ballato. IEEE Trans. Ultrasonics, Ferroelectrics, Frequency Control, 43, 56 (1996).

[26] В.Е. Анкудинов, Д.Д. Афлятунова, М.Д. Кривилев, Г.А. Гордеев. Компьютерное моделирование прочессов переноса и деформаций в сплошных средах. Учеб. пособие. (Ижевск, Изд-во „Удмуртский университет“, 2014).

Редактор Л.В. Шаронова

\section{Energy spending at the formation of elastic-stressed state in the layers of step-graded metamorphic buffer in a heterostructure grown on (001) GaAs substrate}

\author{
A.N. Aleshin ${ }^{1}$, A.S. Bugaev1, O.A. Ruban ${ }^{1}$, \\ V.V. Saraikin ${ }^{1}$, N.Yu. Tabachkova ${ }^{2}$, I.V. Shchetinin ${ }^{2}$ \\ ${ }^{1}$ Mokerov Institute \\ of Ultrahigh Frequency Semiconductor Electronics, \\ Russian Academy of Sciences, \\ 117105 Moscow, Russia \\ ${ }^{2}$ National University of Science and Technology \\ „MISiS“, \\ 119049 Moscow, Russia
}

\begin{abstract}
The $X$-ray reciprocal space mapping, secondary ions mass spectrometry and transmission electron microscopy were employed to characterize the elastic-stressed state of the layers of a metamorphic step-graded buffer in a heterostructure grown on (001) GaAs substrate. It was established that the layers of the buffer are characterized by both lateral and vertical stresses which are caused by the presence of interphase boundaries in the heterostructure. The interphase boundaries block the full relief of stresses and cause the effect of interlayer hardening. The analysis preformed in terms of the linear theory of elasticity shows that the arising elastic-stressed state may be formed as the result of twostage strain process combining both bulk and biaxial compression. Bulk compression increases sufficiently the energy of dislocation free layer and violates a coherence connection between it and the underlying layer.
\end{abstract}

